\title{
KOMBUCHA TEA WITH AND WITHOUT HERBS AS POSSIBLE REMEDY FOR OBESITY
}

\author{
By \\ Fatma El-Zahraa Amin El-Sherif \\ Al-Shymaa Farouk Ali \\ Dept. Of Nutrition \& Food Science, \\ Faculty of Home Economics, Menoufiya \\ University \\ Dept. Of Nutrition \& Food Science, \\ Faculty of Home Economics, \\ Menoufiya University
}

Research Gournal Specific Fducation

Faculty of Specific Fducation

gMansoura University

ISSUE NO. 28, JANUARY. 2013

مجلة بحوث التربية النوعية ـ جامعة المنصورة

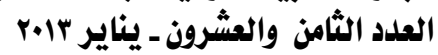




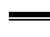

\section{KOMBUGHA TEA WITH AND WITHOUT HERBS AS POSSIBLE REMEOY FOR OBESITY}

\author{
Fatma El-Zahraa Amin El-Sherif*
}

Al-Shymaa Farouk Ali Gheita*

\section{Abstract}

This work was conducted to prepare kombucha tea from both black and white tea to study the possible use of kombucha tea to fight obesity using Sprague dawley male albeno rats. In the study the oral administration of the two kinds of kombucha tea for obese rats carried out to investigate the possible enhancement of slimming, by aid of kombucha tea with two herbal formulations which contained (1) Cornsilk + Juniper + Hawthorn + Thyme; (2) Alfalfa + Dandelion + Horstail + Bearberry. High fat diet used to induce obesity, and continued during 49 days of the feeding trail. Body wieght gain $\%$ (BWG \%), feed intake (FI) and feed effeiciency ratio and some internal organs weights calculated as indication of biological changes. The biochemical parameters were determined in serum to find out the possible changes of liver functions, kidneys functions, lipids profile, creatinine, urea, uric acid and glucose. Nutritional intervention using kombucha white tea plus herbal formulation (2) revealed maxmum slimming with maintaining better the liver and kedneys function, the lipids profile with lowering serum glucose. Histopatiological changes confirmed that of biochemical parameters.

\footnotetext{
"Dept. Of Nutrition \& Food Science, Faculty of Home Economics, Menoufiya University
} 


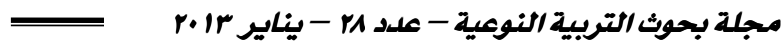

\title{
KOMBUCHA TEA WITH AND WITHOUT HERBS AS POSSIBLE REMEDY FOR OBESITY
}

\author{
Fatma El-Zahraa Amin El-Sherif \\ Al-Shymaa Farouk Ali Gheita*
}

\section{Introduction}

Obesity is a medical condition in which excess body fat has accumulated to the extent that it may have an adverse effect on health (WHO, 2000).

The nutrition transition in Egypt has occurred in the context of abundant dietary energy availability, urbanisation and moderate fat intakes. The prevalence of obesity in adults is very high, particularly among women. The prevalences of diabetes mellitus and of hypertension parallel that of obesity and both are very high.

Rates of early childhood malnutrition remain stubbornly stable and relatively high (Galal, 2002) .

Traditional medicine can treat various infectious and chronic conditions. New antimalarial drugs were developed from the discovery and isolation of artemisinin from Artemisia annua L., a plant used in China for almost 2000 years (WHO, 2008).

Tea is one of the most widely consumed beverage, second only to water (Weisburger, 1997).

The major interest in tea and health stems from the high level of antioxidant tea polyphenols in green tea and black tea (Weisburger, 1997).

Another beverage known as Kombucha is a traditional fermentation of sweetened tea, involving a symbiosis of yeast species and acetic acid bacteria. Despite reports of different yeast species being associated with the fermentation, little is known of the quantitative ecology of yeasts in Kombucha (Teoh et al., 2004).

Using oxytetracycline-supplemented malt extract agar, yeasts were isolated from four commercially available Kombucha products and

Dept. Of Nutrition \& Food Science, Faculty of Home Economics, Menoufiya University 
identified using conventional biochemical and physiological tests. During the fermentation of kombucha beverages, yeasts were enumerated from both the cellulosic pellicle and liquor of the Kombucha. The number and diversity of species varied between products, but included Brettanomyces bruxellensis, Candida stellata, Schizosaccharomyces pombe, Torulaspora delbrueckii and Zygosaccharomyces bailii. Kombucha fermentation is, in general, initiated by osmotolerant species, succeeded and ultimately dominated by acid-tolerant species (Teoh et al., 2004).

This work was conducted to compare between red and white tea, using preparation of kombucha beverage. The effect of two herbal formulations as used with kombucha red and white tea on the slimming of obese rats was also in the scope of this investigation.

\section{MATERIALS AND METHODS}

The kombucha tea culture was prepared as (Frank, 1995 \& Mayser et al., 1995). The herbs (Cornsilk "Zea mays" - Juniper "Juniperus communis" - Hawthorn "Crataegus Laevigata" and Thyme "Thymus vulgaris") as herbal formulation (1) [f. (1)] and (Alfalfa "Medicago sativa" - Dandelion "Taraxacum officinale weber" - Horsetail "Equisetum" and Bearberry "Arctostaphylos uva-ursi") as herbal formulation (2) [f. (2)] were dried at room temperature, then were crumbled into powder. Then added to basal diet at ratio of $10 \%$.

Basic diet prepared according to the following formula (Table A) as mentioned by AIN (Anonymous, 1993), while high fat diet was as cited by Negm (2002). 


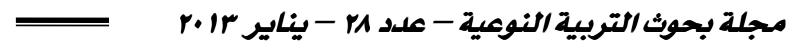

Table(A): Basal and high fat diet components (g/100g)

\begin{tabular}{|c|c|c||}
\hline Ingredients & Basal diet $\%$ & High fat diet $\%$ \\
\hline \hline Casein & 10 & 14 \\
\hline Corn starch & 71 & 45.25 \\
\hline Sunflower oil & 10 & 10 \\
\hline Fiber & 4 & 5 \\
\hline Minerals mixture & 4 & 4 \\
\hline Vitamin mixture & 1 & 1 \\
\hline Tallow & - & 10 \\
\hline Bile salts & - & 0.25 \\
\hline Sucrose & - & 10 \\
\hline DL.Methionine & - & 0.3 \\
\hline Choline chloride & - & 0.2 \\
\hline
\end{tabular}

Male albino rats, Sprague Dawley strain, $(n=28$ rats $)$ were fed on basal diet for one week for acclimatization, then they were fed on high fat diets for one month and fifteen days before starting the experiment. After that, rats (obese rats) were divided into 7 groups (4 rats each), all groups were fed for 49 days as follows:

\section{Groups of male rats:}

- Group (1):Rats fed on high fat diet only as control (Obese rats).

- Group (2):Rats fed on high fat diet $+3 \mathrm{ml}$ Kombucha red-tea.

- Group (3):Rats fed on high fat diet $+3 \mathrm{ml}$ Kpmbucha white-tea.

- Group (4):Rats fed on high fat diet + f. (1) + 3ml Kombucha red-tea.

- Group (5):Rats fed on high fat diet + f. (2) + 3ml Kombucha red-tea.

- Group (6):Rats fed on high fat diet + f. (1) + 3ml Kombucha white-tea.

- Group (7):Rats fed on high fat diet + f. (2) + 3ml Kombucha white-tea.

Kombucha tea was given orally with the help of gastric cannula (Sairam et al., 2001).

Feed intake was recorded daily and body weight gain (BWG) of rats was measured every weak. Also, feed efficiency ratio (FER) was calculated accorrding to Chapman et al., (1959) as the following formulas: 
Final weight - Initial weight

$$
\begin{aligned}
& \mathrm{BWG} \%=\longrightarrow \times 100 \\
& \text { Initial weight } \\
& \text { Gain in body weight }(\mathrm{g})
\end{aligned}
$$

FER $\%=$

Feed intake (g)

The organs (liver, heart, lungs, kidney and spleen) of each animal were removed, washed in saline solution, dried by filter paper and weighted. Kidney and liver were kept in buffered formalin solution (for histopathological examination) according to the methods described by Drury and Wallington (1980).

At the end of experimental period rats were sacrificed and blood samples were collected from the hepatic portal vein into dry clean centrifuge tubes and left to clot in water both $(37 \mathrm{o}$ C.) for half an hour. The blood was centrifuged for 10 minutes at 3000 r.p.m to separate serum; serum was carefully aspirated into clean cuvette tube and stored frozen at $-20 \mathrm{o} C$ till analysis as described by Schermer (1967).

Colorimetric method for total cholesterol (TC) determination according to Richmond (1973).

Enzymatic colorimetric method used to determine triglycerides according to Young (1975).

HDL-cholesterol was determined according to Richmond (1973).

Atherogenic index was calculated according to the formula (VLDL + LDL / HDL) of Kikuchi Hayakawa et al., (1998)

Colorimetric method used to determine AST and ALT according to Reitman and Frankel (1957).

Kinetic determination of ALP activity was determined according to Haussament (1977).

Colorimetric method used to determine serum creatinine according to Henry (1974). 
Enzymatic method used to determine urea according to Patton and Crouch (1977).

The Determination of uric acid in blood was analyzed according to Fowcett \& Scott (1960) .

The data were analyzed using a completely randomized factorial design SAS (1985). When a significant main effect was detected; the mean were separated with the Student New Man Keuls Test. Differences between treatments $(\mathrm{P}<0.5)$ were considered significant using Costat Program. Biological results were analyzed by one way classification ANOVA.

\section{RESULTS AND DISCUSSION}

\section{A-Biological parameters :}

Data presented in tables $(1,2 \& 3)$ showed that obese rats fed on the basal diet indecated +7.9 BWG $\%$, while this value reduced appreciably on feeding with red $(-5.75 \%)$ and white $(-10.04 \%)$ kombucha tea. Percent decrease of BWG \% compared with control group was higher for white ($241.61 \%)$ than red $(-181.1 \%)$ kombucha tea.

Suplemintation of the high fat diet with f. (1) and especially with f. (2) reduced more the BWG \% (compared to unsuplimented feeds), percent decreases were $-207.9 \%$ and $321.58 \%$ respectively when feeding on kombucha red tea.

Much more decrease of BWG \% recorded when feeds supplemented with f. (1) \& f. (2) used with the kombucha white tea; percent decreases of BWG \% were $-243.44 \%$ and $308.77 \%$ respectively.

Therefore it could be stated that kombucha white tea caused more slimming of obese rats; in particular when high fat diet supplemented with the f. (2).

By calculation it was revealed that when obese rats fed on kombucha white tea with $\mathrm{f}$. (2) within six months, the rats may lose about $54 \%$ of body weight, which is a considerable slimming.

The feed intake (FI) (Table 2) revealed that means were not significantly changed due to intake of kombucha tea without and with the 
herbal formulations. This may indecate that kombucha tea and herbal formulations did not change the appetite of rats. Neverthless numerically (nonsignificantly) FI revealed very slight decrease due to feeding on red kombucha tea without and with herbal formulations, provided that f. (2) decreased FI more than (1) very slightly (nonsignificantly). Numarically, kombucha white tea, especially when feeds supplemented with f. (2) reduced FI more than the red kombucha tea with same f. (2). It may be concluded that numerically lowest FI recorded for white kombucha tea plus f. (2). This group (Table $1 \& 2$ ) revealed maxmum significant slimming of rats (least BWG \%), along with numerically maximum decrease of FI.

Table (1): Body weight percent of obese rats as affected by kombucha red and white tea with two herbal formulations

\begin{tabular}{|c||cc|c|c||}
\hline \multicolumn{1}{|c||}{ Parameter } & \multicolumn{4}{c||}{ Body weight gain (BWG \%) } \\
\cline { 2 - 5 } Group & \multicolumn{2}{|c|}{ Mean } & \pm SD & $\begin{array}{c}\% \text { of change of } \\
\text { control }\end{array}$ \\
\hline \hline Control & +7.09 & $\mathrm{a}$ & 0.64 & ---- \\
\hline K. red tea & -5.75 & $\mathrm{~b}$ & 0.90 & -181.1 \\
\hline K. white tea & -10.04 & $\mathrm{c}$ & 1.29 & -241.61 \\
\hline K. red tea + f. (1) & -7.65 & $\mathrm{bc}$ & 2.49 & -207.9 \\
\hline K. red tea + f. (2) & -15.71 & $\mathrm{~d}$ & 2.55 & -321.58 \\
\hline K. white tea + f. (1) & -10.17 & $\mathrm{c}$ & 1.34 & -243.44 \\
\hline K. white tea + f. (2) & -14.66 & $\mathrm{~d}$ & 2.65 & -306.77 \\
\hline LSD & \multicolumn{4}{|c}{3.312} \\
\hline
\end{tabular}

K. : Kombucha

f. : Herbal formulation

Means in the same column with different letters are significantly different and vice versa. 


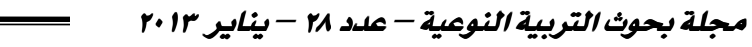

Table (2): Feed intake (FI) of obese rats as affected by kombucha red and white tea with two herbal formulations

\begin{tabular}{|c|cc|c|c||}
\hline \multirow{2}{*}{ Group Parameter } & \multicolumn{4}{|c|}{ Feed Intake FI \% } \\
\cline { 2 - 5 } & Mean & \pm SD & \% of change of control \\
\hline \hline Control & 23.81 & $\mathrm{a}$ & 1.75 & ---- \\
\hline K. red tea & 23.21 & $\mathrm{a}$ & 2.19 & -2.52 \\
\hline K. white tea & 21.84 & $\mathrm{a}$ & 3.08 & -8.27 \\
\hline K. red tea + f. (1) & 23.13 & $\mathrm{a}$ & 3.41 & -2.86 \\
\hline K. red tea + f. (2) & 22.56 & $\mathrm{a}$ & 3.80 & -5.52 \\
\hline K. white tea + f. (1) & 22.60 & $\mathrm{a}$ & 2.49 & -5.08 \\
\hline K. white tea + f. (2) & 22.50 & $\mathrm{a}$ & 3.12 & -5.50 \\
\hline LSD & \multicolumn{3}{|c|}{5.025} \\
\hline
\end{tabular}

K. : Kombucha

f. : Herbal formulation

Means in the same column with different letters are significantly different and vice versa.

Table (3): Feed efficiency ratio of obese rats as affected by kombucha red and white tea with two herbal formulations

\begin{tabular}{||c|cc|c|c||}
\hline \multirow{2}{*}{ Proup } & \multicolumn{4}{|c||}{ Feed efficiency ratio FFR \% } \\
\cline { 2 - 5 } & \multicolumn{2}{|c|}{ Mean } & \pm SD & $\begin{array}{c}\text { \% of change of } \\
\text { control }\end{array}$ \\
\hline \hline Control & 0.016 & $\mathrm{c}$ & 0.00 & ---- \\
\hline K. red tea & 0.014 & $\mathrm{c}$ & 0.001 & -12.5 \\
\hline K. white tea & 0.02 & $\mathrm{bc}$ & 0.01 & +25.0 \\
\hline K. red tea + f. (1) & 0.016 & $\mathrm{c}$ & 0.001 & 0 \\
\hline K. red tea + f. (2) & 0.04 & $\mathrm{a}$ & 0.13 & +150 \\
\hline K. white tea + f. (1) & 0.024 & $\mathrm{bc}$ & 0.003 & +50.0 \\
\hline K. white tea + f. (2) & 0.03 & $\mathrm{ab}$ & 0.007 & +87.5 \\
\hline LSD & \multicolumn{5}{|c}{0.013} \\
\hline
\end{tabular}

K. : Kombucha

f. : Herbal formulation

Means in the same column with different letters are significantly different and vice versa. 
Feed efficiancy ratio "FER" (Table 3) was nonsignificantly decreased due to feeding on kombuche red tea and significantly increased for kombuche white tea, provided that FER was nonsignificantly higher for kombucha white tea than kombucha red tea.

Kombucha red tea with f. (1) showed the same FER value found for control and kombucha red and white tea, while f. (2) raised considerably and significantly the FER compared with unsupplemented kombucha red tea.

Kombucha white tea with f. (1) showed statistically same FER found for that without the herbal formulation. White kombucha red tea with $\mathrm{f}$. (2) ranked numarically FER compared with the unsupplemented diet group. FER showed nonsignificant differences between that of kombucha red and white with the f. (2). These two groups revealed the best FER amoung all treatments (Table 3) and maxmum slimming of obese rats (Table 2).

The effect of kombucha tea as used for slimming was not found in the previous studies, as far as the authors were aware. Nevertheles, according Kotb, Mahasen (2009) when hepercholesterolemic rats recieved 3ml/day of kombucha red or green tea the BWG was reduced significantly; BWG was less than that recorded for healthy control (-) group. It was concluded that kombucha tea decreases the body weight of healthy or hypercholesterolemic rats. The same author found an improvement of FER and decrease of FI when rats received kombucha red and green tea, which was also trended in the present work (Table $2 \& 3$ ).

\section{A- Internal organs weight :}

Data of (Table 4) show the internal organ weights (g) of obese rats as affected by kombucha red and white tea with two herbal formulations. It is evident that the weights of all internal organs for obese (control) rats were relatively high compared to that of treated groups. EL-Nagar (2010) found that due to indution of obesity the internal organs (liver, kidneys, heart, lungs and spleen) weights increased, which reduced upon feeding on a slimming herbal mixture. In present work atrophy (decrease of weights) took place in caes of all kombucha beverages treatments indicating correction of weight and amelioration of inflammations accompanied 


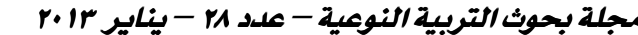

obesity. Kombucha white tea corrected more the increase of organs weights compared to kombucha red tea, and addition of herbal formulations, specially the f. (2) resulted in more decrease of organs weights. Maxmum reduction of internal organs weight recorded for kombucha white tea $+\mathrm{f}$. (2).

Table (4): Internal organs weight ( $\mathrm{g}$ ) of obese rats as affected by kombucha red and white tea with herbal formulations

\begin{tabular}{|c|c|c|c|c|c|c|c|c|c|c|}
\hline \multirow{2}{*}{ Parameter } & \multicolumn{2}{|c|}{ Liver } & \multicolumn{2}{|c|}{ Kidneys } & \multicolumn{2}{|c|}{ Heart } & \multicolumn{2}{|c|}{ Lungs } & \multicolumn{2}{|c|}{ Spleen } \\
\hline & $\begin{array}{l}\text { Mean } \\
\pm \mathrm{SD} \\
\end{array}$ & $\begin{array}{c}\% \text { of } \\
\text { control }\end{array}$ & $\begin{array}{l}\text { Mean } \\
\pm \mathrm{SD}\end{array}$ & $\begin{array}{c}\% \text { of } \\
\text { control }\end{array}$ & $\begin{array}{l}\text { Mean } \\
\pm \mathrm{SD}\end{array}$ & $\begin{array}{c}\% \text { of } \\
\text { control }\end{array}$ & $\begin{array}{l}\text { Mean } \\
\pm \mathrm{SD} \\
\end{array}$ & $\begin{array}{c}\% \text { of } \\
\text { control }\end{array}$ & $\begin{array}{l}\text { Mean } \\
\pm \mathrm{SD}\end{array}$ & $\begin{array}{c}\% \text { of } \\
\text { control }\end{array}$ \\
\hline Control & $\begin{array}{r}6.9 \mathrm{a} \\
\pm 0.04 \\
\end{array}$ & & $\begin{array}{r}1.9 \mathrm{a} \\
\pm 0.15 \\
\end{array}$ & & $\begin{array}{r}1.4 \mathrm{a} \\
\pm 0.24 \\
\end{array}$ & & $\begin{array}{r}2.6 \mathrm{a} \\
\pm 0.16 \\
\end{array}$ & & $\begin{array}{r}1.3 \mathrm{a} \\
\pm 0.08 \\
\end{array}$ & \\
\hline K. red tea & $\begin{array}{r}6.8 \mathrm{~b} \\
\pm 0.02 \\
\end{array}$ & -1.45 & $\begin{array}{r}1.8 \mathrm{~b} \\
\pm 0.12 \\
\end{array}$ & -5.26 & $\begin{array}{r}1.2 \mathrm{~b} \\
\pm 0.13 \\
\end{array}$ & -14.29 & $\begin{array}{r}1.8 \mathrm{~b} \\
\pm 0.13 \\
\end{array}$ & -30.77 & $\begin{array}{l}1.1 \mathrm{~b} \\
\pm 0.01 \\
\end{array}$ & -15.39 \\
\hline $\begin{array}{c}\text { K. white } \\
\text { tea }\end{array}$ & $\begin{array}{r}6.6 \mathrm{c} \\
\pm 0.012 \\
\end{array}$ & -4.35 & $\begin{array}{l}1.8 \mathrm{~b} \\
\pm 0.14 \\
\end{array}$ & -5.26 & $\begin{array}{r}1.0 \mathrm{c} \\
\pm 0.11 \\
\end{array}$ & -28.57 & $\begin{array}{r}1.8 \mathrm{~b} \\
\pm 0.12 \\
\end{array}$ & -30.77 & $\begin{array}{r}1.0 \mathrm{c} \\
\pm 0.07 \\
\end{array}$ & -23.08 \\
\hline $\begin{array}{c}\text { K. red tea } \\
+ \text { f.(1) }\end{array}$ & $\begin{array}{r}6.0 \mathrm{~d} \\
\pm 0.013 \\
\end{array}$ & -13.04 & $\begin{array}{l}1.6 \mathrm{c} \\
\pm 0.10 \\
\end{array}$ & -1.58 & $\begin{array}{l}0.9 \mathrm{c} \\
\pm 0.10 \\
\end{array}$ & -35.71 & $\begin{array}{r}1.6 \mathrm{c} \\
\pm 0.14 \\
\end{array}$ & -38.46 & $\begin{array}{l}0.9 \mathrm{~d} \\
\pm 0.07 \\
\end{array}$ & -30.77 \\
\hline $\begin{array}{c}\text { K. red tea } \\
+ \text { f.(2) }\end{array}$ & $\begin{array}{r}5.7 \mathrm{e} \\
\pm 0.012 \\
\end{array}$ & -17.39 & $\begin{array}{l}1.5 \mathrm{~d} \\
\pm 0.11 \\
\end{array}$ & -21.05 & $\begin{array}{l}0.7 \mathrm{~d} \\
\pm 0.08 \\
\end{array}$ & -50.00 & $\begin{array}{l}1.4 \mathrm{~d} \\
\pm 0.10 \\
\end{array}$ & -46.15 & $\begin{array}{l}0.7 \mathrm{e} \\
\pm 0.01 \\
\end{array}$ & -46.15 \\
\hline $\begin{array}{l}\text { K. white } \\
\text { tea + f.(1) }\end{array}$ & $\begin{array}{r}5.4 \mathrm{f} \\
\pm 0.015 \\
\end{array}$ & -21.74 & $\begin{array}{l}1.3 \mathrm{e} \\
\pm 0.11 \\
\end{array}$ & -31.58 & $\begin{array}{r}0.5 \mathrm{e} \\
\pm 0.07 \\
\end{array}$ & -64.29 & $\begin{array}{r}0.9 \mathrm{e} \\
\pm 0.14 \\
\end{array}$ & -65.39 & $\begin{array}{r}0.6 \mathrm{f} \\
\pm 0.02 \\
\end{array}$ & -53.85 \\
\hline $\begin{array}{l}\text { K. white } \\
\text { tea + f.(2) }\end{array}$ & $\begin{array}{r}5.0 \mathrm{~g} \\
\pm 0.013 \\
\end{array}$ & -27.54 & $\begin{array}{r}1.0 \mathrm{f} \\
\pm 0.10 \\
\end{array}$ & -47.37 & $\begin{array}{r}0.5 \mathrm{e} \\
\pm 0.08 \\
\end{array}$ & -64.29 & $\begin{array}{r}0.8 \mathrm{f} \\
\pm 0.11 \\
\end{array}$ & -69.23 & $\begin{array}{r}0.4 \mathrm{~g} \\
\pm 0.01 \\
\end{array}$ & -69.23 \\
\hline LSD & 0.012 & & 0.094 & & 0.151 & & 0.120 & & 0.08 & \\
\hline
\end{tabular}

K. : Kombucha

f. : Herbal formulation

Means in the same column with different letters are significantly different and vice versa.

\section{B-Biochemical changes :}

\section{a- Liver function enzymes (AST, ALT, ALP)}

AST (Table 5) was highest for control sample (obese rats), while reduced significantly due to intake of kombucha tea. Kombucha white tea 
showed much more decrease of AST activity compared to kombucha red tea; percent decreases as compared with the control sample were $-58 \&$ $48.82 \%$ respictively.

Herbal formulation (1) and specially f. (2) decreased the AST activity more $\tan$ without herbal formulations. This was also found for the kombucha white tea.

Maxmum improvement of liver function (maxmum AST decrease) recorded for kombucha red tea plus f. (1), kombucha white tea when diet supplemented with herbal formulations (1) or (2); percent decrease in comparison with the control group was $79 \%$ for kombucha white tea $+\mathrm{f}$. (2) with significant differences between them.

Table (5): Serum ASTof obese rats as affected by kombucha red and white tea with two herbal formulations

\begin{tabular}{|c|cc|c|c||}
\hline \multirow{2}{*}{ Parameter } & \multicolumn{4}{|c||}{ AST (U/L) } \\
\cline { 2 - 6 } & \multicolumn{2}{|c|}{ Mean } & \pm SD & \% of change of control \\
\hline \hline Control & 38 & $\mathrm{a}$ & 0.89 & ---- \\
\hline K. red tea & 19.5 & $\mathrm{~b}$ & 1.32 & -48.82 \\
\hline K. white tea & 16 & $\mathrm{c}$ & 1.00 & -58 \\
\hline K. red tea + f. (1) & 15.5 & $\mathrm{c}$ & 1.50 & -59.32 \\
\hline K. red tea + f. (2) & 9.25 & $\mathrm{~d}$ & 1.52 & -57.7 \\
\hline K. white tea +f. (1) & 15 & $\mathrm{c}$ & 1.00 & -60.63 \\
\hline K. white tea + f. (2) & 8 & $\mathrm{~d}$ & 1.73 & -79 \\
\hline LSD & \multicolumn{5}{|c||}{2.407} \\
\hline \hline
\end{tabular}

K. : Kombucha

f. : Herbal formulation

Means in the same column with different letters are significantly different and vice versa.

Obese rats revealed highest serum ALT activity (Table 6), which was significantly decreased by the intake of kombucha tea. White kombucha tea lowerd more and significantly the ALT activity in serum, which was decreased more with feeding on f. (1) and specially f. (2). Least serum (ALT) was for kombucha white tea + f. (2) and kombucha red tea + f. (2) with nonsignificant difference between them. 


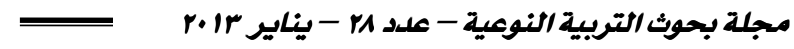

Table (6): Serum ALT of obese rats as affected by kombucha red and white tea with two herbal formulations

\begin{tabular}{||c|cc|c|c||}
\hline \multirow{2}{*}{ Group } & \multicolumn{5}{c||}{ ALT (U/L) } \\
\cline { 2 - 6 } Control & Mean & \pm SD & \% of change of control \\
\hline \hline K. red tea & 17 & $\mathrm{a}$ & 0.98 & ---- \\
\hline K. white tea & 13 & $\mathrm{~b}$ & 0.62 & -23.53 \\
\hline K. red tea + f. (1) & 11 & $\mathrm{c}$ & 1.73 & -35.29 \\
\hline K. red tea + f. (2) & 9 & $\mathrm{~d}$ & 0.87 & -37.06 \\
\hline K. white tea + f. (1) & 10.7 & $\mathrm{c}$ & 0.96 & -47.06 \\
\hline K. white tea + f. (2) & 8 & $\mathrm{~d}$ & 1.00 & -37.06 \\
\hline LSD & \multicolumn{5}{|c||}{1.454} \\
\hline
\end{tabular}

K. : Kombucha

f. : Herbal formulation

Means in the same column with different letters are significantly different and vice versa.

ALP activity of serum was high for obese rats (control), and considerably decreased when obese rats received the kombucha tea. Kombucha white tea showed numerically (nonsignificantly) less liver ALP activity more than kombucha red tea. More significant decrease of ALT was noticed when kombucha red and white tea received with herbal formulations. The effect was more pronounced for white than red, and for $\mathrm{f}$. (2) than f. (1). Least ALP activity recorded for kombucha white tea + f. (2).

Table (7): Serum ALPof obese rats as affected by kombucha red and white tea with two herbal formulations

\begin{tabular}{|c|cc|c|c||}
\hline \multirow{2}{*}{ Parameter } & \multicolumn{4}{|c||}{ ALP (U/L) } \\
\cline { 2 - 6 } & Mean & \pm SD & \% of change of control \\
\hline \hline Control & 301 & $\mathrm{a}$ & 5.57 & ---- \\
\hline K. red tea & 184 & $\mathrm{~b}$ & 4.58 & -38.87 \\
\hline K. white tea & 180 & $\mathrm{~b}$ & 3.16 & -40.20 \\
\hline K. red tea + f. (1) & 138 & $\mathrm{c}$ & 2.65 & -54.15 \\
\hline K. red tea +f. (2) & 115 & $\mathrm{~d}$ & 3.61 & -61.79 \\
\hline K. white tea +f. (1) & 107 & $\mathrm{e}$ & 4.58 & -64.45 \\
\hline K. white tea +f. (2) & 88 & $\mathrm{f}$ & 3.61 & -70.76 \\
\hline LSD & \multicolumn{5}{|c||}{7.040} \\
\hline \hline
\end{tabular}
K. : Kombucha
f. : Herbal formulation

Means in the same column with different letters are significantly different and vice versa. 
AST/ALT ratio was high for obese rats, and decreased significantly when obese rats recieved kombucha red or white tea without and with f. (1) or f. (2) without significant differences between all treatments. Nevertheles, numerically kombucha white tea lowered AST/ALT ratio more than kombucha red tea, which was lowered more (nonsignificantly) with herbal formulations, consumption, and was numerically lower for f. (2) than f. (1). Anyhow lower AST/ALT ratio recorded for kombucha white tea $+f$. (2).

Table (8): Serum AST/ALP ratio of obese rats as affected by kombucha red and white tea with two herbal formulations

\begin{tabular}{|c|cc|c|c||}
\hline \multirow{2}{*}{ Group } & \multicolumn{4}{|c||}{ AST/ALT (ratio) } \\
\cline { 2 - 5 } & Mean & \pm SD & $\begin{array}{c}\text { \% of change of } \\
\text { control }\end{array}$ \\
\hline Control & 2.24 & $\mathrm{a}$ & 0.45 & ---- \\
\hline K. red tea & 1.54 & $\mathrm{~b}$ & 0.26 & -33.04 \\
\hline K. white tea & 1.46 & $\mathrm{~b}$ & 0.18 & -34.82 \\
\hline K. red tea + f. (1) & 1.45 & $\mathrm{~b}$ & 0.23 & -35.27 \\
\hline K. red tea + f. (2) & 1.03 & $\mathrm{~b}$ & 0.23 & -54.02 \\
\hline K. white tea + f. (1) & 1.40 & $\mathrm{~b}$ & 0.17 & -36.16 \\
\hline K. white tea + f. (2) & 1 & $\mathrm{~b}$ & 0.26 & -55.36 \\
\hline LSD & \multicolumn{5}{|c||}{0.513} \\
\hline
\end{tabular}

K. : Kombucha

f. : Herbal formulation

Means in the same column with different letters are significantly different and vice versa.

\section{b-Serum glucose}

Serum glucose (Table 9) of obese rats as affected by kombucha red and white tea without and with f. (1) or (2) was studied. It is evident that obese rats (control) revealed higher serum glucose which was significantly declined when rats received kombucha red tea and specially kombucha white tea. More decrease observed when kombucha red tea received with $\mathrm{f}$. (1) (nonsignificant decrease), but the decrease was significant when kombucha red tea combined with intake of f. (2).

Serum glucose declined when rats received kombucha white tea and consumed herbal formulations with nonsignificant differences between results of f. (1) and f. (2). These groups revealed best results on controling the serum glucose of obese rats. 


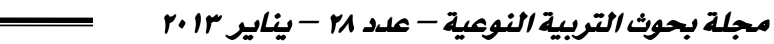

Table (9): Serum glucose of obese rats as affected by kombucha red and white tea with two herbal formulations

\begin{tabular}{||c||cc|c|c||}
\hline \multicolumn{1}{||||}{ Parameter } & \multicolumn{4}{c||}{ Glucose } \\
\cline { 2 - 6 } Group & Mean & \pm SD & \% of change of control \\
\hline \hline Control & 145 & $\mathrm{a}$ & 4.36 & --- \\
\hline K. red tea & 112.3 & $\mathrm{~b}$ & 3.34 & -22.55 \\
\hline K. white tea & 95 & $\mathrm{c}$ & 3.00 & -34.48 \\
\hline K. red tea + f. (1) & 106.7 & $\mathrm{~b}$ & 4.36 & -26.90 \\
\hline K. red tea + f. (2) & 79 & $\mathrm{~d}$ & 6.56 & -45.52 \\
\hline K. white tea + f. (1) & 77.5 & $\mathrm{~d}$ & 2.29 & -46.55 \\
\hline K. white tea + f. (2) & 79 & $\mathrm{~d}$ & 4.58 & -45.52 \\
\hline LSD & \multicolumn{5}{|c||}{7.486} \\
\hline \hline
\end{tabular}

K. : Kombucha

f. : Herbal formulation

Means in the same column with different letters are significantly different and vice versa.

\section{c-Serum lipid profile}

Serum TC, TG, HDL, LDL, VLDL and the AI of obese rats as affected by kombucha red and white tea with two herbal formulationswas studied.

Total cholesterol (TC) was high in obese rats and numerically (nonsignificantly) reduced when obese rats received kombucha red or white tea and kombucha red tea + f. (1). Kombucha red tea + f. (2) and kombucha white tea $+f$. (1) lowered significantly the level of serum TC compared to that of control group. Meanwhile maxmum reduction of serum TC recorded for kombucha white tea $+\mathrm{f}$. (2). 
Table (10): Serum total cholestrol (TC) of obese rats as affected by kombucha red and white tea with two herbal formulations

\begin{tabular}{||c||cc|c|c||}
\hline \multicolumn{1}{|c||}{ Parameter } & \multicolumn{4}{|c||}{ Total Cholestrol } \\
\cline { 2 - 5 } Group & Mean & \pm SD & \% of change of control \\
\hline \hline Control & 110 & $\mathrm{a}$ & 3.61 & --- \\
\hline K. red tea & 108 & $\mathrm{a}$ & 3.61 & -1.82 \\
\hline K. white tea & 106 & $\mathrm{ab}$ & 2.65 & -3.64 \\
\hline K. red tea +f. (1) & 105 & $\mathrm{ab}$ & 3.61 & -0.91 \\
\hline K. red tea + f. (2) & 103 & $\mathrm{~b}$ & 2.65 & -6.36 \\
\hline K. white tea + f. (1) & 104 & $\mathrm{~b}$ & 3.61 & -5.45 \\
\hline K. white tea +f. (2) & 100 & $\mathrm{c}$ & 2.65 & -9.09 \\
\hline LSD & \multicolumn{5}{|c|}{5.976} \\
\hline \hline
\end{tabular}

K. : Kombucha

f. : Herbal formulation

Means in the same column with different letters are significantly different and vice versa.

Serum TG was high in obese control rats, but nonsignificantly decreased when feeding with kombucha red tea $(-6.10 \%)$. More and significant reduction of TG was found when obese rats received kombucha white, kombucha red tea + f. (1) and kombucha red tea + f. (2) (-14.78 to $18.26 \%)$. Appreciable more reduction of serum TG was noticed when rats received kombucha white tea with $\mathrm{f}$. (1) $(-27,83 \%)$.

Nevertheless maxmum TG reduction $(-42.48 \%)$ was found with rats intake of kombucha white tea $+f$. (2). 
Table (11): Serum triglycerides (TG) of obese rats as affected by kombucha red and white tea with two herbal formulations

\begin{tabular}{||c||cc|c|c||}
\hline \hline \multicolumn{1}{|c||}{ Parameter } & \multicolumn{5}{c||}{ Triglyceride } \\
\cline { 2 - 6 } Group & Mean & \pm SD & \% of change of control \\
\hline \hline Control & 115 & $\mathrm{a}$ & 2.65 & ---- \\
\hline K. red tea & 108 & $\mathrm{a}$ & 1.73 & -6.10 \\
\hline K. white tea & 98 & $\mathrm{~b}$ & 6.00 & -14.78 \\
\hline K. red tea + f. (1) & 95 & $\mathrm{~b}$ & 3.00 & -17.39 \\
\hline K. red tea + f. (2) & 94 & $\mathrm{~b}$ & 5.57 & -18.26 \\
\hline K. white tea + f. (1) & 83 & $\mathrm{c}$ & 5.00 & -27.83 \\
\hline K. white tea + f. (2) & 65 & $\mathrm{~d}$ & 4.58 & -42.48 \\
\hline LSD & \multicolumn{3}{|c||}{7.779} \\
\hline \hline
\end{tabular}

K. : Kombucha

f. : Herbal formulation

Means in the same column with different letters are significantly different and vice versa.

Lowest serum HDL was found for obese control rats, which was raised when rats receivead kombucha red tea $(+20 \%)$. More increase $(+25$ to $+28.33 \%$ ) noticed when obese rats fed with kombucha white tea, kombucha red tea $+\mathrm{f}$. (2). Maxmum elevation of HDL in serum achieved when using kombucha white tea + f. (1) and kombucha white tea + f. (2) $(+33.33 \%$ for both).

Table (12): Serum high denisty lipoprotein cholesterol (HDL) of obese rats as affected by kombucha red and white tea with two herbal formulations

\begin{tabular}{||c||cc|c|c||}
\hline \multicolumn{1}{|c||}{ Parameter } & \multicolumn{5}{c||}{ HDL } \\
\cline { 2 - 5 } Group & Mean & \pm SD & \% of change of control \\
\hline \hline Control & 60 & $\mathrm{c}$ & 5.29 & ---- \\
\hline K. red tea & 72 & $\mathrm{~b}$ & 3.00 & +20 \\
\hline K. white tea & 75 & $\mathrm{ab}$ & 2.00 & +25 \\
\hline K. red tea +f. (1) & 76 & $\mathrm{ab}$ & 3.61 & +26.67 \\
\hline K. red tea + f. (2) & 77 & $\mathrm{ab}$ & 3.46 & +28.33 \\
\hline K. white tea + f. (1) & 80 & $\mathrm{a}$ & 3.61 & +33.33 \\
\hline K. white tea +f. (2) & 80 & $\mathrm{a}$ & 2.65 & +33.33 \\
\hline LSD & \multicolumn{5}{|c|}{6.167} \\
\hline
\end{tabular}

K. : Kombucha

f. : Herbal formulation

Means in the same column with different letters are significantly different and vice versa. 
The serum LDL of obese control group was high (48 mg/dl). LDL decreased significantly when rats received kombucha red tea $(-70 \%)$, kombucha white tea $(-76.25 \%)$ and kombucha red tea + f. (1) $(-79.17 \%)$. Cosiderable significant reduction of LDL recorded for kombucha red tea + f. (2), kombucha white tea + f. (1) and kombucha red tea + f. (2) (-84.58 to $85.42 \%$ ) with nonsignificant differences between them.

Table (13): Serum denisty lipoprotein cholesterol (LDL) of obese rats as affected by kombucha red and white tea with two herbal formulations

\begin{tabular}{|c||cc|c|c||}
\hline \multicolumn{1}{|c||}{ Parameter } & \multicolumn{4}{c||}{ LDL } \\
\cline { 2 - 5 } & Mean & \pm SD & \% of change of control \\
\hline \hline Control & 48 & $\mathrm{a}$ & 3.00 & ---- \\
\hline K. red tea & 14.4 & $\mathrm{~b}$ & 0.96 & -70 \\
\hline K. white tea & 11.4 & $\mathrm{c}$ & 0.90 & -76.25 \\
\hline K. red tea + f. (1) & 10 & $\mathrm{c}$ & 1.00 & -79.17 \\
\hline K. red tea +f. (2) & 7.2 & $\mathrm{~d}$ & 0.75 & -85 \\
\hline K. white tea + f. (1) & 7.4 & $\mathrm{~d}$ & 0.72 & -84.58 \\
\hline K. white tea + f. (2) & 7 & $\mathrm{~d}$ & 0.05 & -85.42 \\
\hline LSD & \multicolumn{5}{|c|}{2.171} \\
\hline \hline
\end{tabular}

K. : Kombucha

f. : Herbal formulation

Means in the same column with different letters are significantly different and vice versa.

The level of serum low denisty lipoprotien cholesterol (VLDL) of obese rats fed all the time of experiment with high fat diet. Control group (not received kombucha beverage) showed the higher level of VLDL (23 $\mathrm{mg} / \mathrm{dl})$. Kombucha red tea lowered slightly $(-6.09 \%)$ the VLDL , which was markedly and significantly decreased (-14.78 to $-27.83 \%)$ compared to control group when rats treated with kombucha white tea, kombucha red tea + f. (1), kombucha red tea + f. (2) and kombucha white tea + f. (1). Maxmum and sharp sicnificant reduction (-43.48 \%) of VLDL was found for kombucha white tea $+\mathrm{f}$. (2). 


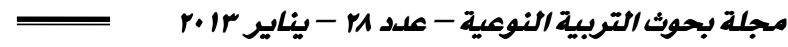

Table (14): Serum very low denisty lipoprotein cholesterol (VLDL) of obese rats as affected by kombucha red and white tea with two herbal formulations

\begin{tabular}{|c||cc|c|c||}
\hline \hline \multicolumn{1}{|c||}{ Parameter } & \multicolumn{4}{c||}{ GLDL } \\
\cline { 2 - 6 } Group & Mean & \pm SD & \% of change of control \\
\hline \hline Control & 23 & a & 0.89 & --- \\
\hline K. red tea & 21.6 & ab & 1.77 & -6.09 \\
\hline K. white tea & 19.6 & bc & 1.71 & -14.78 \\
\hline K. red tea + f. (1) & 19 & bc & 2.08 & -17.39 \\
\hline K. red tea + f. (2) & 18.8 & bc & 1.82 & -19.26 \\
\hline K. white tea + f. (1) & 16.6 & $\mathrm{c}$ & 1.31 & -27.83 \\
\hline K. white tea + f. (2) & 13 & $\mathrm{~d}$ & 1.55 & -43.48 \\
\hline LSD & \multicolumn{4}{|c||}{3.088} \\
\hline \hline
\end{tabular}

K. : Kombucha

f. : Herbal formulation

Means in the same column with different letters are significantly different and vice versa.

Athesogenic index (VLDL + LDL / HDL) (AI) was high for obese control rats, while was decreased significantly and greatly in all treatments with nonsignificant difference between them (-57.63 to $-78.80 \%)$. Lowest numerical serum AI recorded for kombucha white tea + f. (2) group, indecating that this treatment was the best.

Table (15): Atherogenic index (AI) of obese rats as affected by kombucha red and white tea with two herbal formulations

\begin{tabular}{||c||cc|c|c||}
\hline \multicolumn{1}{|c||}{ Parameter } & \multicolumn{4}{c||}{ Atherogenic index } \\
\cline { 2 - 5 } Group & Mean & \pm SD & \% of change of control \\
\hline \hline \multicolumn{1}{|c||}{ Control } & 1.18 & $\mathrm{a}$ & 0.27 & ---- \\
\hline K. red tea & 0.5 & $\mathrm{~b}$ & 0.10 & -57.63 \\
\hline K. white tea & 0.4 & $\mathrm{~b}$ & 0.26 & -66.10 \\
\hline K. red tea + f. (1) & 0.38 & $\mathrm{~b}$ & 0.12 & -67.80 \\
\hline K. red tea + f. (2) & 0.34 & $\mathrm{~b}$ & 0.13 & -71.19 \\
\hline K. white tea + f. (1) & 0.3 & $\mathrm{~b}$ & 0.16 & -74.58 \\
\hline K. white tea + f. (2) & 0.25 & $\mathrm{~b}$ & 0.10 & -78.80 \\
\hline LSD & \multicolumn{5}{|c|}{0.336} \\
\hline \hline
\end{tabular}

K. : Kombucha

f. : Herbal formulation

Means in the same column with different letters are significantly different and vice versa. 


\section{d- Renal function}

Levels of serum creatinine, urea and uric acid of obese rats during feeding on high fat diet as affected by kombucha red and white tea without and with herbal formulations were determined (Table 16).

Obese rats showed relatively high serum creatinine level, which was slightly and nonsignificantly decreased. Nonsignificant but numaric decrease was found also for kombucha red and white tea, kombucha red tea + f. (1) and (2) and kombucha white tea + f. (1) groups. Neverthless compared to control group, significant and considerable decrease $(-44.44 \%)$ recorded for kombucha white tea $+\mathrm{f}$. (2) group; this treatment resulted in maxmum reduction of serum creatinine.

Table (16): Serum creatinine of obese rats as affected by kombucha red and white tea with two herbal formulations

\begin{tabular}{||c||cc|c|c||}
\hline \multicolumn{1}{|c||}{ Parameter } & \multicolumn{4}{c||}{ Creatinine } \\
\cline { 2 - 6 } Group & \multicolumn{2}{|c||}{ Mean } & \pm SD & \% of change of control \\
\hline \hline Control & 0.9 & $\mathrm{a}$ & 0.30 & ---- \\
\hline K. red tea & 0.8 & $\mathrm{ab}$ & 0.26 & -11.11 \\
\hline K. white tea & 0.8 & $\mathrm{ab}$ & 0.17 & -11.11 \\
\hline K. red tea + f. (1) & 0.75 & $\mathrm{ab}$ & 0.50 & -16.67 \\
\hline K. red tea + f. (2) & 0.73 & $\mathrm{ab}$ & 0.20 & -18.89 \\
\hline K. white tea + f. (1) & 0.65 & $\mathrm{ab}$ & 0.50 & -27.78 \\
\hline K. white tea + f. (2) & 0.5 & $\mathrm{~b}$ & 0.10 & -44.44 \\
\hline LSD & \multicolumn{4}{|c||}{0.337} \\
\hline \hline
\end{tabular}

K. : Kombucha

\section{f. : Herbal formulation}

Means in the same column with different letters are significantly different and vice versa.

Serum urea (Table 17) of obese rats was relatively high and reduced significantly when rats fed on kombucha beverages. Maxmum reduction of serum urea recorded for kombucha white tea $+\mathrm{f}$. (1) $(-44.05 \%)$ with nonsignificant difference between them.

Serum of control obese rats had significantly higher uric acid level (Table 18), which decreased significantly in all kombucha beverages 
treatments. Maxmim reduction of uric acid in serum recorded for kombucha white tea + herbal formulatio (2) $(-75.94 \%)$.

Table (17): Serum urea of obese rats as affected by kombucha red and white tea with two herbal formulations

\begin{tabular}{|c|c|c|c|c|}
\hline \multirow{2}{*}{ Group } & \multicolumn{4}{|c|}{ Urea } \\
\hline & \multicolumn{2}{|c|}{ Mean } & $\pm \mathrm{SD}$ & $\%$ of change of control \\
\hline Control & 42 & $\mathrm{a}$ & 3.00 & ---- \\
\hline K. red tea & 26.5 & $\mathrm{~cd}$ & 2.33 & -36.9 \\
\hline K. white tea & 30.8 & $\mathrm{~b}$ & 2.00 & -26.67 \\
\hline K. red tea + f. (1) & 27 & $\mathrm{~cd}$ & 1.49 & -35.7 \\
\hline K. red tea + f. (2) & 28.6 & $\mathrm{bc}$ & 1.39 & -31.9 \\
\hline K. white tea + f. (1) & 23.5 & d & 1.32 & -44.05 \\
\hline K. white tea + f. (2) & 26 & $\mathrm{~cd}$ & 1.18 & -38.10 \\
\hline LSD & \multicolumn{4}{|c|}{4.201} \\
\hline
\end{tabular}

K. : Kombucha

f. : Herbal formulation

Means in the same column with different letters are significantly different and vice versa.

Table (18): Serum uric acid of obese rats as affected by kombucha red and white tea with two herbal formulations

\begin{tabular}{||c||cc|c|c||}
\hline \multicolumn{1}{|c||}{ Parameter } & \multicolumn{5}{c||}{ Uric acid } \\
\cline { 2 - 6 } Group & Mean & \pm SD & \% of change of control \\
\hline \hline Control & 3.2 & $\mathrm{a}$ & 0.26 & ---- \\
\hline K. red tea & 2 & $\mathrm{~b}$ & 0.20 & -37.5 \\
\hline K. white tea & 2.2 & $\mathrm{~b}$ & 0.26 & -31.25 \\
\hline K. red tea + f. (1) & 2 & $\mathrm{~b}$ & 0.26 & -37.5 \\
\hline K. red tea + f. (2) & 1.93 & $\mathrm{~b}$ & 0.17 & -39.69 \\
\hline K. white tea + f. (1) & 1.93 & $\mathrm{~b}$ & 0.31 & -39.69 \\
\hline K. white tea + f. (2) & 0.77 & $\mathrm{c}$ & 0.15 & -75.94 \\
\hline LSD & \multicolumn{5}{|c||}{0.444} \\
\hline
\end{tabular}
K. : Kombucha
f. : Herbal formulation

Means in the same column with different letters are significantly different and vice versa. 


\section{C- Histopathological study :}

\section{a- Liver:}

Liver of rat from group (2) (Kombucha red tea) showed focal hydropic degeneration of hepatocytes (Photo 2), slight hepatocellular vacuolization and portal infiltration with leucocytes (Photo 3). Slight kupffer cells activation is the only histopathological change observed in liver of rat from group (3) (Kombucha-white tea) (Photo 4). However liver of rat from group (4) (Kombucha-red tea + f. (1)) revealed slight kupffer cells activation, portal infiltration with leucocytes (Photo 5) and presence of small vacuoles in the cytoplasm of hepatocytes (photo 6) as well as focal dilation and congestion of hepatic sinusoids (Photo 7).

Examined sections of rat from group (5) (Kombucha-red tea + f. (1)) revealed no changes except slight kupffer cells activation (photo 8). However, liver of rat from (6) (Kombucha-white tea + f. (1)) showed slight granularity of the cytoplasm of hepatocytes (Photo 9). Moreover liver of rat from group (7) (Kombucha-white tea + f. (2)) revealed focal kupffer cells activation (Photo 10), slight vacuolations of hepatocytes and portal infiltration with leucocytes.

\begin{tabular}{|c|c|}
\hline $\begin{array}{l}\text { Photo (1): Liver of (control"-") rats } \\
\text { from group (1) showing the } \\
\text { normal histological structure } \\
\text { of hepatic lobule (H and E } \\
\text { x400). }\end{array}$ & $\begin{array}{l}\text { Photo (2): Liver of rat from group (2) } \\
\text { (Kombucha-red tea) showing } \\
\text { hydropic degeneration of } \\
\text { hepatocytes (H and E X 400). }\end{array}$ \\
\hline
\end{tabular}




\begin{tabular}{|c|c|}
\hline & \\
\hline $\begin{array}{l}\text { Photo (3): Liver of rat from group (2) } \\
\text { (Kombucha-red tea) showing } \\
\text { hepatocellular vacuolization } \\
\text { and portal infiltration with } \\
\text { leucocytes (H and E X 400). }\end{array}$ & 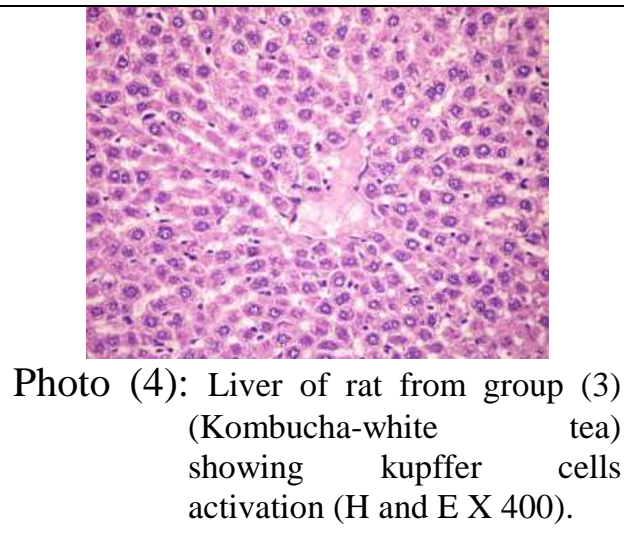 \\
\hline $\begin{array}{l}\text { Photo (5): Liver of rat from group (4) } \\
\text { (Kombucha-red tea + f. (1)) } \\
\text { showing kupffer cells } \\
\text { activation and portal } \\
\text { infiltration with Leucocytes } \\
\text { (H and } E \text { X 400). }\end{array}$ & $\begin{array}{l}\text { Photo (6): Liver of rat from group (4) } \\
\text { (Kombucha-red tea + f. (1)) } \\
\text { showing kupffer cells } \\
\text { activation and presence of } \\
\text { small in the cytoplasm of } \\
\text { hepatocytes (H and } \mathrm{X} 400) .\end{array}$ \\
\hline $\begin{array}{l}\text { Photo (7): Liver of rat from group (4) } \\
\text { (Kombucha-red tea }+\mathrm{f} .(1)) \\
\text { showing dilatation and } \\
\text { congestion of hepatic } \\
\text { sinusoids (H and } \mathrm{E} X 400) .\end{array}$ & $\begin{array}{l}\text { Photo (8): Liver of rat from group (5) } \\
\text { (Kombucha-red tea }+ \text { f. (2)) } \\
\text { showing kupffer cells } \\
\text { activation (H and E X 400). }\end{array}$ \\
\hline
\end{tabular}




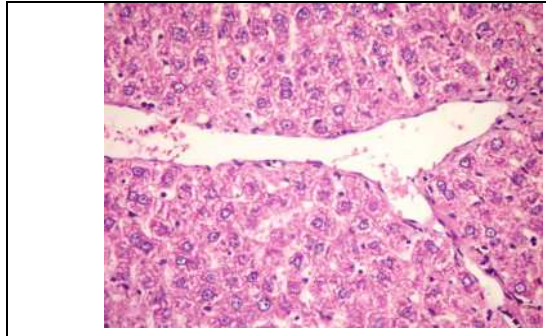

Photo (9): Liver of rat from group (6) (Kombucha-white tea + f. (1)) showing slight granularity of the cytoplasm of hepatocytes (H and $\mathrm{E}$ X 400).

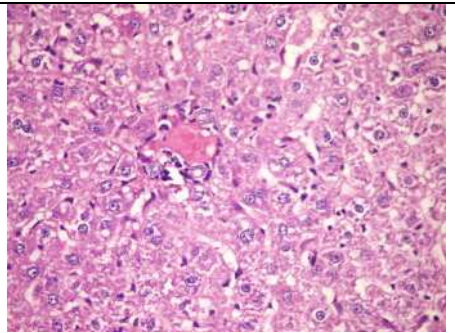

Photo (10): Liver of rat from group (7) (Kombucha-white tea + f. (2)) showing kupffer cells activation (H and $\mathrm{E} \times 400)$.

\section{b- Kidneys :}

kidneys of rat from group (2) (Kombucha-red tea) showed focal vacuolations of opithelial lining renal tubules, focal tubular necrosis associated with leucocytic cells infiltration, focal apoptosis of renal epithelium and slight peritubular leucocytic cells infiltration. Only some examined sections from group (3) (Kombucha-white tea ) revealed focal vacuolations of renaltubular epithelium whereas, other sections from this group showed no histopathological changes Moreover, very few sections from group (4) Kombucha-red tea + f. (1) showed atrophy of glumerular tuft, distension of Bowmen's space and peritubular leucocytic cells infiltration (Photo 12), whereas, other sections from groups (4, 5 \& 6) (Kombucha-red tea + formulations "1 \& 2" and Kombucha-white tea + f. (1)) revealed no histopathological changes (Photos 13 ). Only some sections from group (7) Kombucha-white tea $+\mathrm{f}$. (2) showed congestion of renal blood vessels and slight lypertrophy of glumerular tuft (Photo 14), whereas, other sections from this group (Kombucha-white tea + f. (2)) revealed no histopathological changes. As in case of liver, kidneys showed negligible changes, when rats fed on Kombucha tea, specially (Kombucha-white tea + f. (2)). 


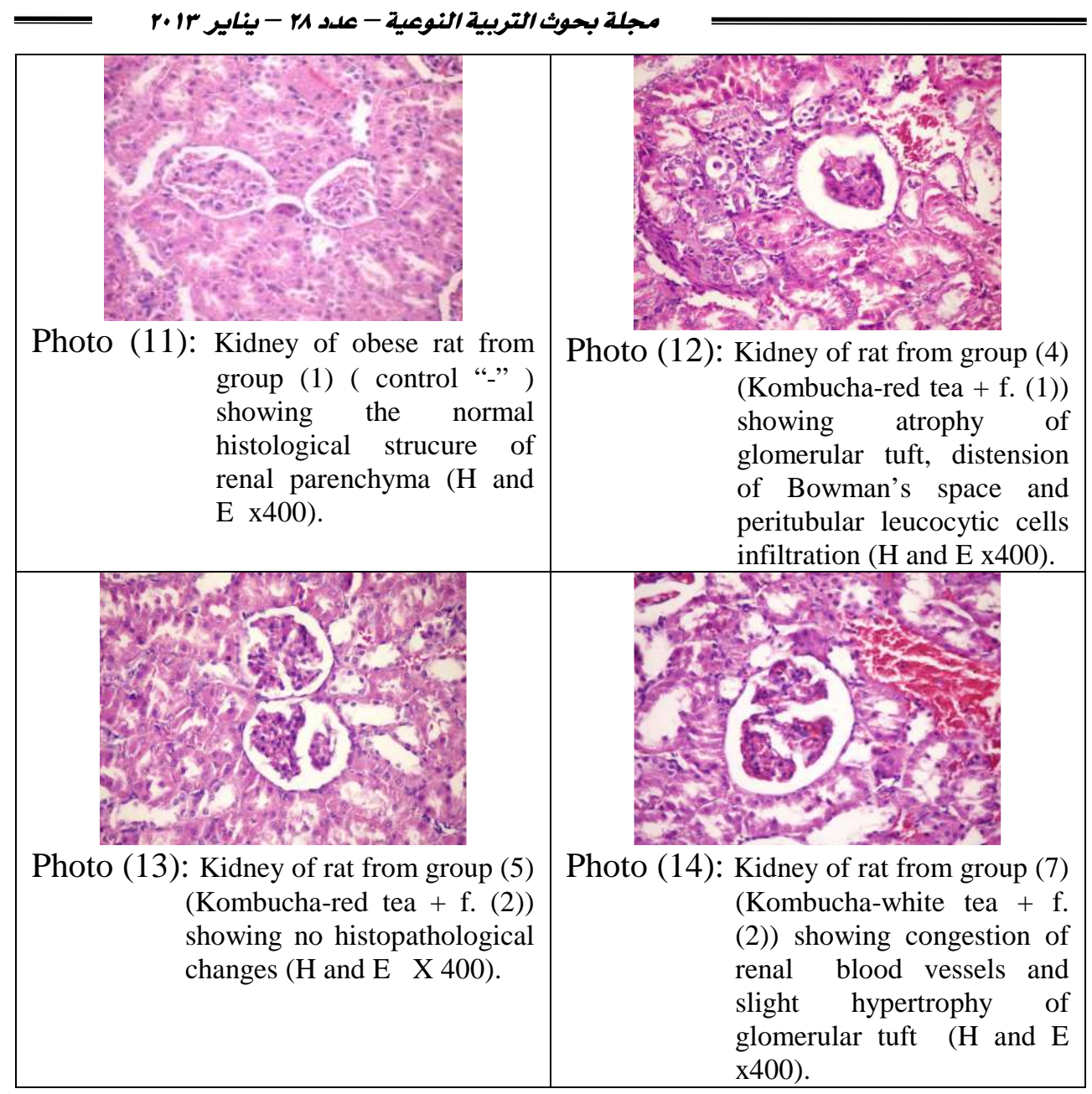

\section{c-Heart:}

Some examined sections from group (2) (Kombucha-red tea) showed focal myocarditis, whereas, other sections from this group showed no histopathological changes. Moreover, heart of rats from groups $(3,4,5,6$ \& 7) (Kombucha-white tea with or without f. (1) \& (2), and Kombucha-red tea $+\mathrm{f}$. (1) or (2)) revealed no histopathological changes.

\section{d- Lungs :}

Lung of rat from group (2) (Kombucha-red tea) showed focal thickening of interstitial tissue (Photo 16) and focal interstitial pneumonia Moreover lung of rat from group (3) (Kombucha-white tea) revealed 
thickening of interstitial tissue. Lung of rat from group (4) (Kombucha-red tea $+\mathrm{f}$. (1)) showed focal perivasculitis, focal thickening of interstitial tissue associated with focal atlectasis (Photo 17). No histopathological changes observed in lung of rat from group (5) Kombucha-red tea + f. (2).

However, lung of rat from group (6) Kombucha-white tea + f. (1) revealed focal vacuolations of alveolar epithelium. Only some examined sections from group (7) Kombucha-white tea + f. (2) revealed focal interstitial pneumonia (Photo 18), whereas, other sections showed no histopathological changes.

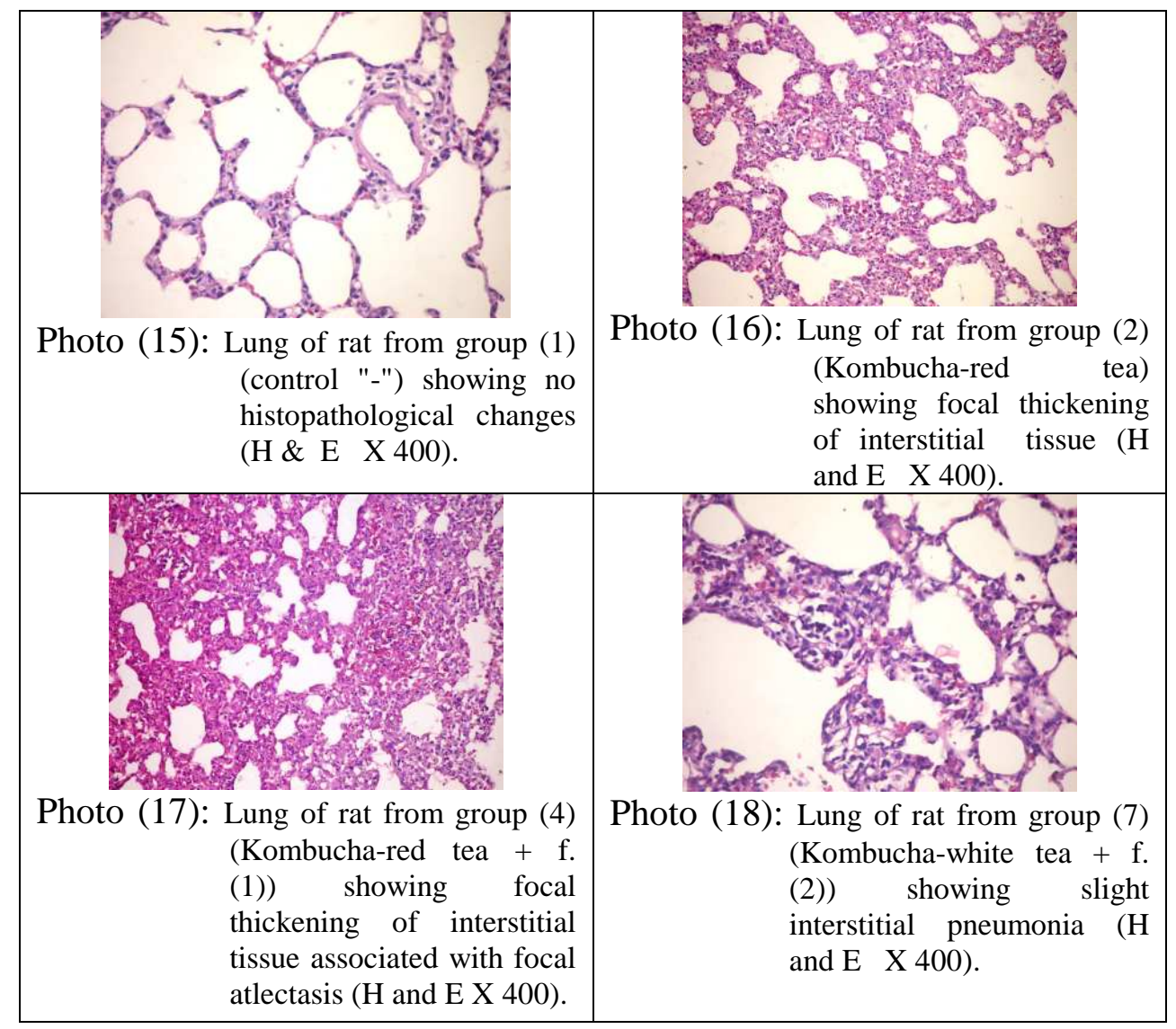


e-Spleen :

Spleen of rat from group (2) (Kombucha-red tea) showed slight lymphocytic necrosis. Examined sections from group (3) (Kombucha-white tea) revealed no histopathological changes. Slight lymphocytic necrosis was the only histopathological finding observed in spleen of rat from group (4) Kombucha-red tea +f. (1) (Photos 20, $21 \&$ 22).

Meanwhile, spleen of rats from groups (5, $6 \& 7$ ) (Kombucha-red tea + f. (2) \& Kombucha-white tea + f. (1) \& (2)) revealed no histopathological changes (Photos 23, $24 \& 25$ ).

Finally feeding the obese rats with Kombucha red + white tea with or without added formulation had no side effects on the histopathology of liver, kidney, lung, heart \& spleen tissues, which indicates safety of their use for obese rats.

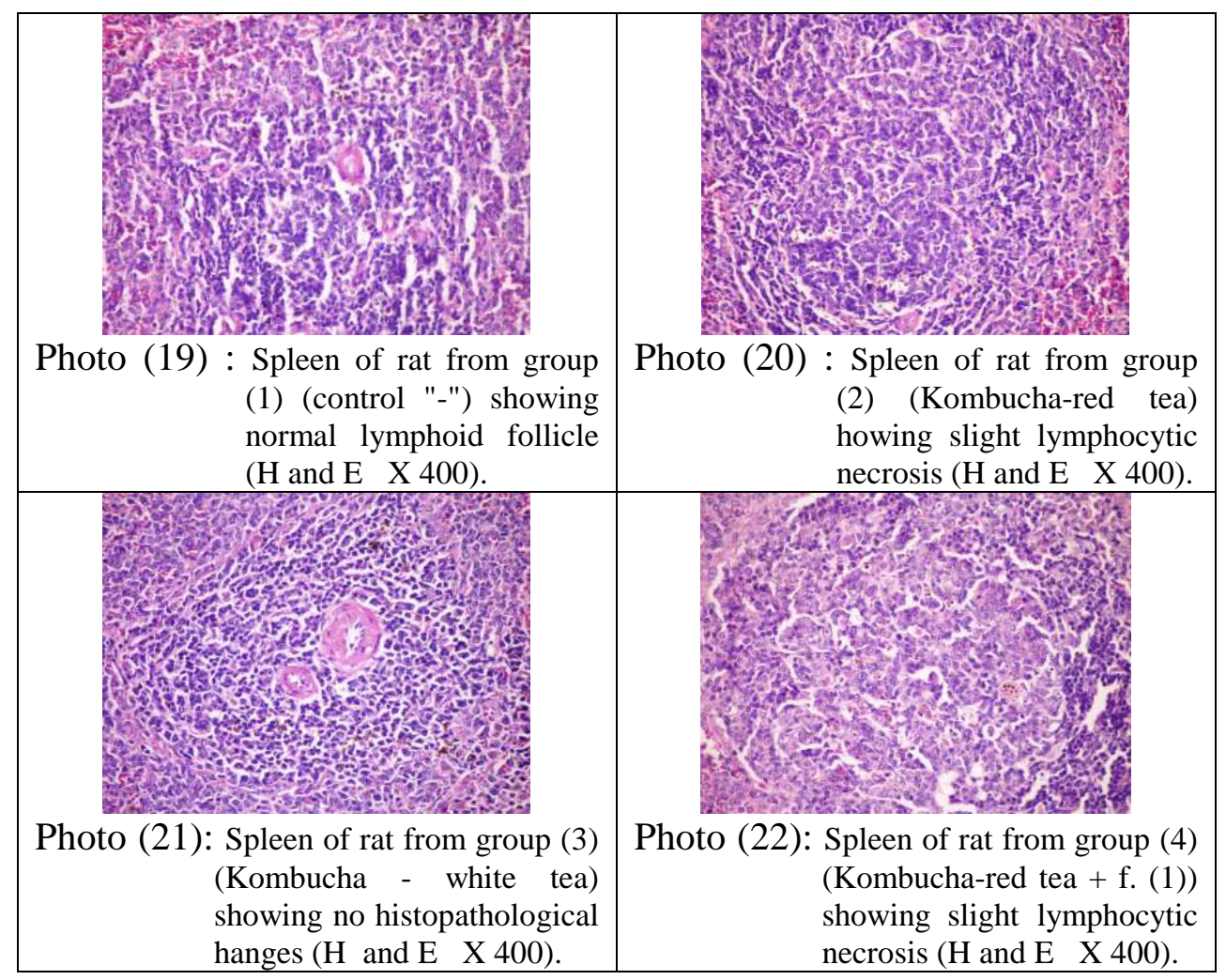




\begin{tabular}{|c|c|}
\hline $\begin{array}{l}\text { Phe } \\
\text { Photo (23): Spleen of rat from group (5) } \\
\text { (Kombucha-red tea + f. (2)) } \\
\text { showing no histopathological } \\
\text { changes (H and E X 400). }\end{array}$ & $\begin{array}{l}\text { Phot } \\
\text { Photo (24): Spleen of rat from group (6) } \\
\text { (Kombucha-white tea + f. (1)) } \\
\text { showing no histopathological } \\
\text { changes (H and E X 400). }\end{array}$ \\
\hline $\begin{array}{r}\text { Photo (25): Spleen } \\
\text { (Kombi } \\
\text { showin } \\
\text { changes }\end{array}$ & $\begin{array}{l}\text { Den (7) } \\
\text { of rat from group (7) } \\
\text { cha-white tea + f. (2) } \\
\text { no histopathological } \\
\text { (H and E X 400). }\end{array}$ \\
\hline
\end{tabular}




\section{REFERENCES:}

- Anonymous (1993): Purified diet for laboratory rodent: Final Report. American Institute of Nutrition. (AIN) J. Nutrition, 123: 1939-1951 .

- Chapman D. G.; Castillo, R. and Campbell, J. A. (1959): Evaluation of proteins in foods. Canadian Journal of Biochemistry and Physiology, 37: 679683 .

- Drury, R.A.B. and Wallington, E.A. (1980): Carleton's Histological Technique. 5th Ed. Oxford, UK, Oxford University Press.

- El-Nagar, M.M.G.A. (2010): Effect of Some Plant Materials and Herb as Used forCorrecting Obesityof Male Albino Rats. Ph.D. Thesis. Faculty of Home Economics, Menoufiya University.

- Fowcett, A.M. and Scott, H. (1960): Determination of urea in serum by enzymatic colorimetric method. J . Clin. Path., 13: 156.

- Frank, G.W. (1995): Kombucha. La Boissan au Champion de Langue Vie, W. Ennsthaler. Styer, Austria.

- Galal, O.M. (2002): The nutrition transition in Egypt: Obesity, undernutrition and the food consumption context. Public Health Nutr., 5(1A): 141-8 .

- Haussament, T.U. (1977): Qualitative determination of serum alkaline phosphatase. Clin. Chem. Acta, 35: 271-273 .

- Henry, R. J. (1974): Clinical Chemistry Principles and Techniques. 2nd Ed., Harper and Row Publ., New York, USA.

- Kikuchi-Hayakawa; Onodera, N.; Matsubara, S.; Yasudo, E.; Chonan, O. Takahashi, R. And Ishikawa, F. (1998): Effect of soy milk and bifidobacterium fermented soy milk on lipid metabolism in aged ovariectomized rats. Bioscience, Biotechnology and Biochemistery, 62 (9): 1688-1692 .

- Kotb, Mahasen A.M. (2009): Chemical, Technological and Biological Studies on the Utilization of Kombucha Tea. Ph.D. Thesis, Faculty of Home Economics, Menoufiya University.

- Mayser, P; Fromme, S.; Leitzmann, C. and Grunder, K. (1995): The yeast spectrum of the tea fungus kombucha. Mycoses, 38: 289-295 .

- Negm, D.R. (2002): Effect of Some Common Herbs on Weight Redution in Obese Rats. M.Sc. Thesis, Faculty of Home Economics, Menoufiya University . 
- Patton, C.J. and Crouch, S.R., (1977): Spectrophotometric and kinetics investigation of the Berthelot reaction for the determination of ammonia. Analytical Chemistry, 49: 464-469 .

- Reitman, S. \& Frankel, S. A. (1957): Colorimetric method for the determination of serum glutamic oxalacetic and glutamic pyruvic transaminases. Amer. J. Clin. Pathol., 28: 56-63, 1957.

- Richmond, W. (1973): Preparation and properties of bacterial cholesterol oxidase from Nocardia sp. and its application to the enzymatic assay of total cholesterol in serum. Clinical Chemistry, 19: 1350-1 356.

- Sairam R.K.; Chandrasekhar, V. and Srevastava, G.C. (2001): Comparison of hexaploid and tetraploid wheat cultivars in their responses to water stress. Biologia Plantarum, 44: 89-94.

- SAS (1985): SAS User Guide: Basic Version, SAS Institute, Inc USA .

- Schermer, S. (1967): The Blood Morphology of Laboratory Animals, 4th Ed. Philadelphia: Davis.

- Teoh, A.L., Heard, G. and Cox, J. (2004): Yeast ecology of Kombucha fermentation. Int. J. Food Microbiol., 95 (2): 119-26.

- Weisburger J. H. (1997): Tea and health: A historical perspective. Cancer Lett., 114 (1-2): 315-7.

- WHO (2000): Obesity: Preventing and Managing the Global Epidemic. Peport of a World Health Organization Consultation, Geneva, p.6

- WHO (2008): World Health Organization, Fact Sheet $\mathrm{N}^{\circ} 134$.

- Young, D. S. (1975): Determination of GOT. Clin. Chem, 3: 21-25 . 


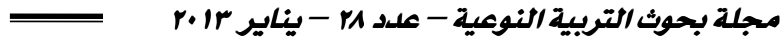

\section{شاي الكمبوتشا هع وبدون الأعشاب كعلاج للسمنة}

الشيماء فاروق علمغيتّة

* فاطمةالزهراءأمس.

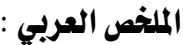

أجري هذا البحث لإعداد شاي الكمبوتشا من الشاي الأسود والشاي الأبيض على حـد سواء

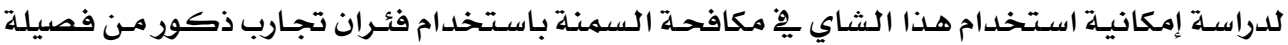

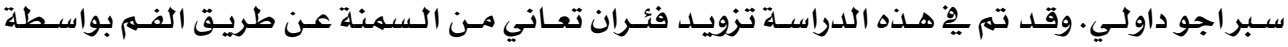

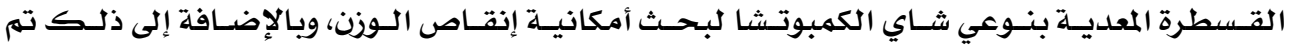

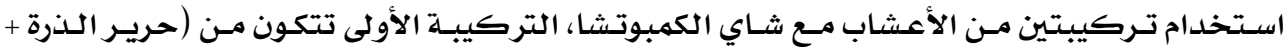

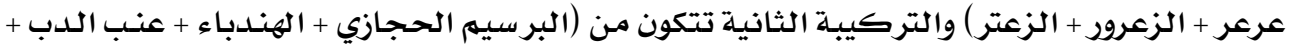

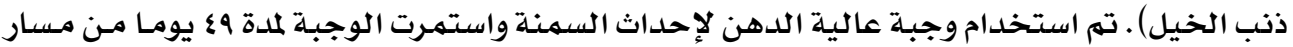

تم حسـاب النسبة المئوية للزيادة يِّوزن الجسم ومقدار الطعام المأخوذ ونسبة كفـاءة الغـذاء

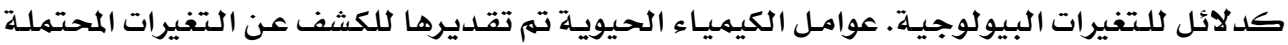

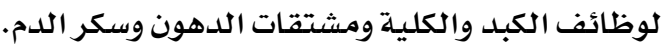

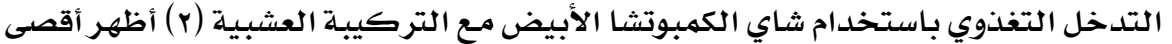

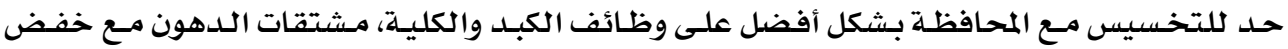

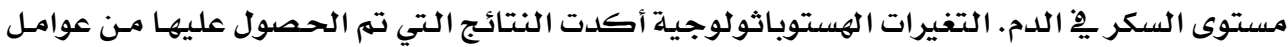
الكيمياء الحيوية السئرئ. 